\title{
Study of Triple Vessel Wave Pattern by Doppler Studies in Low Risk and High Risk Pregnancies and Perinatal Outcome
}

\author{
*Sureendhar Mohan ${ }^{1}$, Paarthipan Natarajan ${ }^{2}$, Sandeep Madineni ${ }^{3}$, \\ Rajasekhar K.V. ${ }^{4}$. \\ ${ }^{I}$ AssistantProfessor, Department of radiodiagnosis,Meenakshi Medical college Hospital and Research \\ Institute (MMCH \& RI), Kanchipuram. \\ ${ }^{2}$ Professor, Department of radiodiagnosis,Meenakshi Medical college Hospital and Research \\ Institute (MMCH \& RI), Kanchipuram. \\ ${ }^{3}$ Post graduate, Department of radiodiagnosis, Meenakshi Medical college Hospital and Research \\ Institute (MMCH \& RI), Kanchipuram. \\ ${ }^{4}$ Professor and Head, Department of radiodiagnosis, Meenakshi Medical college Hospital and Research \\ Institute (MMCH \& RI), Kanchipuram.
}

\begin{abstract}
Objectives:Role of Triple vessel umbilical, middle cerebral and uterine artery wave pattern by colour Doppler study in low and high risk pregnancies in relation to perinatal outcome.

Methods:Fifty (50)patients with gestational age between 31-40weeks who werediagnosed to have severe preeclampsia, preeclampsia with IUGR were studied andsubjected to colour Doppler ultrasonography. Findings of Doppler studies werecorrelated with the following adverse Perinatal outcomes; Perinatal deaths,Emergency CS for foetal distress, Low Apgar score (5 min Apgar <7), and admissionto NICU for complications of low birth weight. Pregnancy outcome was consideredto be Uneventful or Favourable when the above complications were absent.The uterine artery, Umbilical artery and the Middle cerebral artery Dopplerindices for the corresponding gestational age were compared with the referencevalues. The uterine artery and Umbilical artery Doppler indices were consideredabnormal if the value was above the 95th percentile of previously published values forgestational age. The Middle cerebral artery Doppler index was considered abnormal ifthe value was below the 5th percentile of previously published values for gestationalage. A single cut off value (1.08) was used for Cerebroplacental Ratio (MCA PI/UAPI), above which the cerebro placental ratio was considered normal and below whichit was considered abnormal.

Results: Acceptable wave forms were obtained from Uterine artery, MCA and UA inall these cases. All the cases were followed up for the perinatal outcome.Cerebroplacental ratio had higher sensitivity (95\%) and NPV (85\%) than UAPI(Sensitivity 66.66\%, NPV 79.40\%) and MCA PI (Sensitivity 83.33\%, NPV 77.27\%), UAPI had higher specificity (93.10\%) and PPV (87.5\%) compared to cerebroplacentalration (Specificity 87\%, PPV 88\%) and MCAPI (Specificity 85\%, PPV 89.28\%).Diagnostic accuracy of Cerebroplacental ratio (Accuracy=90\%) was betterthan UAPI (Accuracy=82\%) and MCA PI (Accuracy=84\%) in predicting adverseoutcomes.

Conclusion: In clinically diagnosed severe preeclampsia and suspected IUGR pregnancy,both Cerebroplacental ratio and Umbilical artery PI are strong predictors of adverseperinatal outcome. Cerebroplacental ratio is most sensitive and Umbilical artery PI ismost specific index in predicting adverse outcome. Absent or reversed end diastolicflow in an umbilical artery is an ominous finding associated with major adverseperinatal outcome and mortality.
\end{abstract}

Keywords: High risk pregnancy; severe preeclampsia, IUGR and Triple vesselDoppler study; Perinatal outcome.

\section{Introduction}

Pre-eclampsia is one of the leading causes of maternal and fetal morbidity andmortality. It affects 2-5\% of pregnancies and is principally disease of first term pregnancy.Pre eclampsia is a specific syndrome characterized by reduced organ perfusion secondaryto vasospasm and endothelial pathophysiology. Almost all the morbidity being due tomultisystemic manifestations in many organs including brain, liver, kidney and placenta.IUGR is a common complication of pre-eclampsia and is due failure of normal placentalinvasion and development.

The primary pathology is the impairment of placental perfusion, which may beattributed to abnormal placentation of maternal vascular disease. Impaired placentalperfusion is believed to result from insufficient invasion of maternal spiral arterioles by thetrophoblast early in gestation. Consequently, the crucial hemodynamic changes seen innormal pregnant uterine vasculature - that is shift from low volume high resistance to highvolume low resistance environment does not take place2. This leads to increased 
vascularresistance and decreased utero placental perfusion. The subsequent placental ischemia maylead to production of free radicals damaging the endothelial cells.As a result of impaired uteroplacental blood flow manifestations of pre-eclampsiamay be seen in feto placental unit. These include IUGR, oligohydramnios, placentalabruption, fetal hypoxia, perinatal death and non-reassuring fetal status found onantepartum fetal surveillance by Doppler ultrasound.

The main goals of antepartum fetal surveillance are to identify foetusesatincreased risk forperinatal mortality and morbidity. Doppler ultrasound allows anoninvasive assessment offetalhaemodynamic. Doppler investigation of the umbilicalarteries provides information concerning perfusion of the fetoplacental circulation, whileDoppler study of fetal vesselsdetects the haemodynamic rearrangements that occurinresponse to fetal hypoxia.

Umbilical artery (UA) Doppler velocimetry is the most rigorously evaluatedtest among the noninvasive tests of fetal wellbeing. Several authors have reported a lowend diastolic velocity in the umbilical artery, a consequence of high flow resistance incapillaries of the terminal villi.Ameta-analysis of randomized controlled trials of UA Doppler velocimetry inhigh risk pregnancies (mainly pregnancies with associated pregnancy inducedhypertension and suspected IUGR) demonstrated that its use was associated with a trendtowards reduction of perinatal mortality8. In response to prolonged fetal hypoxic stress,circulatory adaptation occurs, resulting in redistribution of the cardiac output to provide aconstant oxygen supply to the brain and other essential organs (i.e., heart and adrenalglands). This compensatory adjustment, on which the brain sparing effectisbased,associated with a rise in diastolic velocities in Doppler cerebral artery waveforms. Thisrise is considered a manifestation of cerebral vasodilatation, causing a decrease inDoppler indices such as the pulsatility index. At cordocentesis, a significantcorrelation has been observed between hypoxemia in fetuses with IUGR and abnormalmiddle cerebral artery (MCA) pulsatility index (PI.).

Recent studies indicate that the cerebroplacental ratio of pulsatility index ofMCA and UA is the most sensitive Doppler index for predicting perinatal outcome infetuses with IUGR.In the majority of the severely growth retarded fetuses, sequential deterioration ofarterial and venous Doppler precedes biophysical profile score deterioration. At least onethird of fetuses show early signs of circulatory deregulation 1 week before biophysicalprofile deterioration, and in most cases, Doppler deterioration preceded biophysicalprofile deterioration by 1 day. This indicates the significance of Doppler study in thesepatients for early detection of fetal compromise.

Differences in study design, including the criteria for patient selection, thedefinition of adverse outcomes, different cut off levels between normal and abnormal testresults makes direct comparison difficult. Our study was an effort at establishing the roleof uterine artery; UA and MCA Doppler Ultrasound in predicting adverse perinatal outcome in the clinically suspected iugr and preeclampsia Pregnancies and to determine therole of Doppler velocimetry in clinical management of such pregnancies.

\section{Objectives:}

1.To analyze the blood flow in uterine artery, umbilical artery and middle cerebral arteryusing Doppler ultrasound in a group of patients with severe preeclampsia and severepreeclampsia with IUGR

2.To assess the value of Doppler ultrasound in analysing the perinatal outcome inpatients with severe preeclampsia and severe preeclampsia and IUGR.

3.To evaluate the role of Doppler ultrasound in the management of patients with severepreeclampsia and severe preeclampsia and IUGR.

\section{Materials And Methods}

The study was conducted on fifty women with high risk pregnancies withinclusion criteria and fifty women with low risk pregnancies who were admitted todepartment of obstetrics and gynaecologyatMeenakshi Medical college hospitalandresearch institute, Kanchipuram fromNovember 2010 to July 2012.

\section{Study Subjects}

Patients with inclusion criteria admitted/attending to department of obstetricsand gynaecology were assigned into two groups $\mathrm{A}$ and $\mathrm{B}$. Each group included 50 cases.GroupA included high risk pregnancies with inclusion criteria and group B includedwomen with low risk pregnancies as control groups.

\section{Inclusion Criteria}

All antenatal cases more than 30 weeks of gestation clinically diagnosed aspregnancy induced hypertension with following inclusion criteria are included:

$\square \square$ Singleton pregnancies.

Pregnant womenwith history and physical findings suggestive of

Severe preeclampsia, 
IUGR (EFW $<10 \mathrm{TH}$ percentile for gestational age)

Severe preeclampsia plus IUGR.

Those who gave consent for the study.

\section{Exclusion Criteria}

The pregnancies with following conditions were excluded;

Cardiovascular disease

Multiple gestations

Fetuses with congenitalanomalies

Renal disease

Essential hypertension prior to pregnancy and other high risk pregnancies

Intrauterine death at the time of first Doppler examnation.

The gestational age was based on last menstrual period (LMP), ultrasoundbiometry performed before the 20th gestational week, when the LMP is uncertain or notknown and early ultrasound before 13 weeks has not been performed". Follow up Doppler studies were performed if clinically indicated to determine afavourable or a worsening trend in the Doppler indices. However, only the results of thefirst Doppler ultrasound were used for analysis of perinatal outcome.

\section{Procedure:}

The patient was explained about the non-invasive/ atraumatic nature of the procedure.Syntheticultragel was applied liberally over the abdomen to get a good acousticcoupling. The instrument used was VOLUSON S6 PROColour Doppler ultrasound machinewith a convex transducer of 2-5 $\mathrm{MHz}$ frequency. Doppler wave form was obtained afterlocalizing the vessels by B mode real time scanner. Pulsed Doppler was used to get theDoppler signals after localizing the vessels. The maximum Doppler shift frequencieswere obtained and various ratios were calculated from each vessel. Doppler examinationwas done when foetus was in apneic state to avoid the influence of fetal respiration onDoppler signals.

\section{Identification of various arteries and their criteria}

1. Uterine Artery: Colour Doppler facilitates identification of the uterine arterysubstantially. The uterine signal was obtained per abdomen by pointing the probe in theiliac fossa towards the lower para-cervical area. In the colour mode, the uterine artery isseen to cross the external iliac artery, just after its origin from the internal iliac artery andthis point was taken as the sampling point. Doppler wave forms were obtained. Values ofS/D ratio, RI and PI >95th percentile as per the Harrington et al Doppler indices andpersistent early diastolic notch is considered abnormal.

2. Umbilical Artery: Flow velocity waveforms from umbilical artery can be easilyobtained, for this colour flow is not usually needed. Doppler signals can be acquired fromdifferent points in cord, usually from mid portion of cord. Values of S/D ratio, RI and PI>95th percentile as per the Harrington et al Doppler indices, presence of absent enddiastolic velocity (AEDV) and reversed end diastolic velocity (REDV) were consideredabnormal.

3. Middle Cerebral Artery (MCA): MCA was visualized in transverse axial view offetal head at a slightly more caudal plane than the one used for BPD. PI and RI $<5^{\mathrm{TH}}$ percentile as per the Harrington et al Doppler indices were considered abnormal.

\section{Outcome criteria:}

Doppler US results were analysed for prediction of perinatal outcome. Outcomevariables included are:

Birth Weight (less than 10th percentile)

- Perinatal death

- Emergency CS for fetal distress

- Low APGAR score (5 min APGAR score less than 7)

- Admission to NICU for complications of Low Birth Weight.

Pregnancy was considered to have "Adverse outcome" when any of the followingcomplications were present

Perinatal death

Emergency CS for fetal distress

5 minute Apgar score of less than 7

Admission to $\mathrm{XCU}$ for complications of low birth weight.

Pregnancy outcome was considered to be Uneventful or Favourable when theabove complications were absent. The outcome for each pregnancy was obtained byexamining the labor ward records and neonatal intensive care unit records whereverappropriate. The UA Pulsatility index ratios were considered abnormal if

DOI: $10.9790 / 0853-1603061423 \quad$ www.iosrjournals.org $\quad 16 \mid$ Page


the value wasabove the 95th percentile of previously published values for gestational age. The MCA pulsatilityindex was considered abnormal if the value was below the 5th percentile ofpreviously published values for gestational age.The MCA/UA PI ratio (cerebroplacentalratio) is considered abnormal when it is less than 1.08 as given by theGramellini $\mathrm{D}$ et al.

\section{Results}

In the present study out of fifty cases of study groups, 34 showed positiveDoppler indices in any or combinations of the three vessels studied. The remaining 16cases showed normal Doppler indices in all the three vessels studied.

\section{Discussion}

Preeclampsia and Intrauterine growth restriction is associated with increased risk of perinatalmorbidity, mortality and impaired neurological development. It is a challenge to differentiate the foetus with pathologic growth restriction and hence at risk forperinatal complications from constitutionally small but healthy foetus. Dopplervelocimetry is a non-invasive technique that evaluates abnormal fetal haemodynamicthattakes place in response to changes in placental resistance. A Doppler index that reflectsboth of these areas can be useful for identifying fetuses with increased placental anddecreased cerebral resistance.

Umbilical artery and middle cerebral artery Doppler ultrasound clearly depicts the information about placental resistance and the changes in the fetal haemodynamicinresponse to it. Umbilical arteries Doppler reflects the maldevelopment of the placentaltertiary stem villi which increases the placental resistance leading to growth retardedfoetus. Middle cerebral artery Doppler has enabled the confirmation of brain sparing effectin IUGR. Hence we chose the UA PI, MCA PI and MCA PI/UA PI i.e. cerebroplacentalratio as the tool for predicting the perinatal out come in IUGR.

We studied the Doppler index of umbilical artery only after 30th week, because inagreement with Schulman, Gramellini, we believe that it is difficult to define normalor abnormal umbilical flow velocity before 30th week, with the exception of absent enddiastolic flow velocity after 20th week.

We studied the Doppler index of middle cerebral artery because it is the mostaccessible artery to see the cerebral redistribution as it is the main branch of the circle ofWillis and carries $80 \%$ of the blood flow to the ipsilateral cerebral hemisphere, a constant $3 \%-7 \%$ of cardiac output throughout gestation.

The MCA PI and UA PI values for the corresponding gestational age werecompared with reference values given by Harrington et al27normograms. MCA PI wasconsidered abnormal when it is less than 5thpercentile for that gestational age and UA PIwas considered abnormal when it is more than 95thpercentile for the corresponding gestationalage. It is possible to use a single cut off value for cerebroplacental ratio after 30thweekbecause cerebral-umbilical Doppler ratio does not vary significantly between 30thand 40thweeks as reported by Waldimiroff et al12who observed a significant differences incerebroplacental ratio only between weeks 26-38. After 26thweek, the statistical comparison showed no significant differences between the intervals considered.Arbeille11et al also found the cerebral-placental ratio constant during thepregnancy and suggested 1 as the cut off value and all values below 1 were considered abnormal. We considered the study of Gramelliniet al13that cerebroplacental ratio less than 1.08 as abnormal.

We have studied about 50 pregnancies with preeclampsia and clinical suspicion ofIUGR. $70 \%$ of neonates $(\mathrm{n}=35)$ had birth weight of less than $2.5 \mathrm{~kg}$. Of the 50 neonates, 19 neonates were admitted to NICU, 8 neonates had 5 min Apgar score of less than 7 and 15 babies were born by emergency caesarean section for fetal distress. There were 8 neonatal deaths. Of the 8 neonatal deaths, 1 case had reversal of diastolic flow and 5 hadabsent diastolic flow.

\section{Normal and abnormal Doppler wise distribution of cases in Present study group and reference studies}

\begin{tabular}{|c|c|c|}
\hline & Normal & Abnormal \\
\hline Bhatt CJ et al & $44 \%$ & $56 \%$ \\
\hline U. Gupta et al & $45 \%$ & $55 \%$ \\
\hline Present Study & $32 \%$ & $68 \%$ \\
\hline
\end{tabular}

As compared with other studies present study also had majority of cases withabnormal DopplerUmbilical artery - It was found to have low sensitivity of $66.6 \%$ when compared toMAC PI and cerebroplacental ratio. The sensitivity was comparable with that of FongKW etalandGramellini et al. 
Study Of Triple Vessel Wave Pattern Bydoppler Studies In Low Risk And High.....

\begin{tabular}{|c|c|c|c|}
\hline & Fong K W et al & Gramellini et al & Present study \\
\hline Sensitivity & $44.7 \%$ & $64 \%$ & $66.6 \%$ \\
\hline Specificity & $86.6 \%$ & $90.7 \%$ & $93.1 \%$ \\
\hline PPV & $54 \%$ & $72.7 \%$ & $87.5 \%$ \\
\hline NPV & $81.7 \%$ & $86.7 \%$ & $79.4 \%$ \\
\hline
\end{tabular}

The specificity of the UA PI $93.1 \%$ was found to be better than other variables. The specificity was comparable with the above mentioned studies. The UA PI is effectiveto rule in the possibility of adverse perinatal out come when it is abnormal. The PositivePredictive Value of UA PI $87.5 \%$ was more than that of MCA PI and Cerebroplacentalratio. It indicated the likelihood of adverse perinatal outcome in growth retarded foetuswith abnormal UA PI. The positive predictive value was higher when compared to allother studies. The negative predictive value $79.4 \%$ obtained in our study was comparablewith the above mentioned studies. This was less than that of MCA PI andcerebroplacental ratio.

Our findings confirms the results of Fong KW et al, Chan et alandGramellinietalthat abnormal UAPI is associated with adverse outcome like NICU admission forlow birth weight and low Apgar scores than the one with normal UA PI. It provides themost useful information for differentiating fetuses already compromised or likely tobecome compromised from those that are non compromised. Our findings agree withHarringtonetalthat umbilical artery can be normal in term and near term withabnormal middle cerebral artery.

Middle cerebral artery - was found to have a sensitivity of $83.3 \%$ less than that ofcerebroplacental ratio and more than that of UA PI. The values were not comparable withthe below mentioned studies.

\begin{tabular}{|c|c|c|c|}
\hline & Fong K W et al & Gramellini et al & Present study \\
\hline Sensitivity & $72.4 \%$ & $24 \%$ & $83.3 \%$ \\
\hline Specificity & $58.1 \%$ & $100 \%$ & $85 \%$ \\
\hline PPV & $37.7 \%$ & $100 \%$ & $89.28 \%$ \\
\hline NPV & $85.7 \%$ & $77.30 \%$ & $77.27 \%$ \\
\hline
\end{tabular}

It showed specificity $85 \%$. It agrees with Fong etalthat MCA PI is less specificthan cerebroplacental ratio and UA PI. The study had more number of false positivevalues. There are several possible explanations for the low Specificity of the MCApulsatility index for adverse perinatal outcome. Among several published normogramsfor MCA PI.

thecutoff values for an abnormal MCA pulsatility index are similar upto about 30 weeks gestational age but differ after 32 weeks. The normograms we chose touse for analysis are from the largest published crosssectional study by Harrington K etal.

Positive predictive value of MCA PI $89.28 \%$ in predicting adverse perinataloutcome is more than that for other variables, which can be attributed to the less falsepositivevalues.The negative predictive value of $77.27 \%$ is comparable with that Gramellini et alstudy. It is more usefulness in ruling out the possibility of adverse perinatal outcome.

Cerebroplacental ratio - It had the highest sensitivity value of $95.6 \%$ more thanany other variable. The values were not comparable with any other study because ofvariation in the prevalence of IUGR.

The highest sensitivity of cerebroplacental ratio indicates its usefulness ofcerebroplacental ratio in ruling out the possibility of adverse perinatal outcome in IUGRwhen the ratio is normal for the gestational age. It showed the specificity of $87 \%$ which isless compared to UA PI and better than the MCA PI. The values were comparable withFongetalstudy

\begin{tabular}{|c|c|c|c|}
\hline & Fong K W et al & Gramellini et al & Present study \\
\hline Sensitivity & $51.3 \%$ & $68 \%$ & $95 \%$ \\
\hline Specificity & $80.6 \%$ & $98.4 \%$ & $83 \%$ \\
\hline PPV & $48.1 \%$ & $94.4 \%$ & $88 \%$ \\
\hline NPV & $82.5 \%$ & $88.8 \%$ & $85 \%$ \\
\hline
\end{tabular}

Cases with Doppler abnormality in Present study group and reference studies

\begin{tabular}{|c|c|c|}
\hline & $\begin{array}{c}\text { Abnormal } \\
\text { Ut.A. S/D }\end{array}$ & $\begin{array}{c}\text { Abnormal } \\
\text { UA S/D }\end{array}$ \\
\hline Trudinger et al & $47.33 \%$ & $40 \%$ \\
\hline U. Gupta et al & $55 \%$ & $39 \%$ \\
\hline Saxena et al & $77 \%$ & $40 \%$ \\
\hline Khalid et al & $94.44 \%$ & $80.56 \%$ \\
\hline Present Study & $82.30 \%$ & $81.70 \%$ \\
\hline
\end{tabular}


Present study has shown majority of cases (85.71\%) with abnormal umbilicalartery S/D ratio, which is comparable to the study conducted by Khalid et al. In otherstudies majority showed abnormal uterine artery S/D ratio.

In the present study, majority of the cases (63\%) with abnormal Doppler indiceshad NICU stay where as Cutis L LoweryJrstudy showed $86 \%$ of NICU admissionswith abnormal Doppler indices

\begin{tabular}{|c|c|}
\multicolumn{2}{|c|}{ Distribution } \\
\hline & $\begin{array}{c}\text { \% of Abnormal } \\
\text { Doppler with IUGR }\end{array}$ \\
\hline Fleischer et al & $67 \%$ \\
\hline Bhatt CJ et al & $60 \%$ \\
\hline Khalid et al & $30.56 \%$ \\
\hline Present study & $37.14 \%$ \\
\hline
\end{tabular}

Of IugrIn Abnormal Doppler Indices

Fleischer et aland Bhatt CJ et al showed $67 \%$ and $60 \%$ of IUGR in abnormalDoppler indices whereas in the present study it was $37.14 \%$ and in the study done byKhalid et al59 it was $30.56 \%$.

AedvAndRedf - Perinatal Mortality

\begin{tabular}{|c|c|}
\hline Bhatt CJ et al & $50 \%$ \\
\hline Battaglia et al & $50 \%$ \\
\hline Present Study & $100 \%$ \\
\hline
\end{tabular}

$100 \%$ mortality was seen in cases with reversed diastolic flow and absentdiastolic flow. This confirms the findings of Karsdropetal, which showed that absentand reversed diastolic flow is better indicator of the adverse perinatal outcome.

The current study has shown that absent or reversed end - diastolic flow in theumbilical artery is strongly associated with major perinatal morbidity with mortality. Thishas been well recognized in the literature that there is strict correlation between theabnormal UA PI and poor perinatal outcome in IUGR. Studies have shown that absentand reversed diastolic flow in the umbilical artery is associated with increased perinatalmortality and morbidity.

Our results in evaluating the usefulness of umbilical artery and middle cerebralartery Doppler in predicting the adverse perinatal outcome in preeclampsia and IUGRindicate that both abnormal umbilical Doppler indices and cerebral-umbilical ratio arestrong predictors of adverse outcome in IUGR. The MCA PI alone is not a reliableindicator when used alone. The combination of umbilical and fetal cerebral Dopplerindices may increase the utility of Doppler ultrasound in clinically suspected IUGR.

\section{Summary}

Fifty (50) patients diagnosed to have severe preeclampsia, preeclampsia withIUGR with gestational age between 31-40 weeks were studied and subjected tocolour Doppler ultrasonography. Uterine, umbilical and fetal middle cerebralarteries were studied. S/D ratio of $>2.6, \mathrm{RI}>0.58$, persistent early diastolic notchin uterine artery; $\mathrm{S} / \mathrm{D}$ ratio of $>3$, RI $>0.7$, AEDV and REDV in umbilical artery; $\mathrm{RI}<0.7$, $\mathrm{PI}<1.3$ in middle cerebral artery were considered abnormal. The resultswere correlated with parameters of perinatal outcome.

In our study, age group 2024 years was the common group. The mean maternalage was 23.1 years.

$\square \square$ Out of 50 cases studied, 34 (68\%) showed positive Doppler indices in any of thethree vessels studied. The remaining $16(32 \%)$ cases showed normal Dopplerindices in all the three vessels studied.

$\square \square$ Among abnormal 34 cases, 29(85\%) cases, 25(74\%) cases and 15 (44\%)had abnormal Middle cerebral artery, uterine artery and umbilical artery Dopplerindices respectively.

$\square \square$ Maximum number of abnormal cases $(95 . \%)$ ) were induced and delivered.

$\square \square$ Babies of 19 cases (55\%) with abnormal Doppler indices had NICU stay whereas4 babies (8\%) of the cases with normal Doppler indices had NICU stay.

$\square \square$ Among abnormal cases, 8 babies (24\%) had APGAR score $<7$ compared to 1 baby(3\%) in normal cases $(\mathrm{p}<0.001)$.

$\square \square 36 \%$ of normal cases and $45.5 \%$ of abnormal cases had babies with birth weightin the range of 1.5 to 1.99

Kg. 5 babies (14\%) of abnormal cases had $<1 \mathrm{~kg}$ birthweight and none of the babies of normal cases had $<1 \mathrm{~kg}$ birth weight.

Comparison of mean birth weight between Normal $(1.94 \pm 0.40 \mathrm{Kg})$ and Abnormal(1.49 \pm 0.39$)$ was highly significant [ $\mathrm{t}=4.56, \mathrm{p}<0.001]$

$\square \square$ Number of babies with SGA in abnormal Doppler indices group were 13(37.14\%) when compared to 4 $(16 \%)$ in normal Doppler indices group $\left(\square^{2}=5.63, \mathrm{p}<0.05\right)$. 
Babies of 21 cases $(60 \%)$ with abnormal Doppler indices had neonatalcomplicationswhere as only 7 babies $(28 \%)$ had neonatal complications innormal Doppler indices group $(, \mathrm{p}<0.001)$.

$\square \square$ There were 8 perinatal deaths in abnomal Doppler indices, out of which 4 werestill born and another 4 were neonatal deaths.

$\square \square$ In 5 patients with AEDV there were 2 still born, 3 neonatal deaths and 1 case withREDF had early neonatal death accounting for $100 \%$ Perinatal mortality in bothAEDV REDF.

\section{Conclusion}

Pre eclampsia is associated with significant fetal morbidity and mortality.

$\square \square$ There is progressive fall of vascular resistance in uterine, placental andumbilical arteries as gestational age increases. This will result in high enddiastolic blood flow in all these blood vessels.

$\square \square$ Abnormal uterine, umbilical artery and middle cerebral artery Doppler flowvelocitmetry studies associated with severe form of hypertension and higherincidence of IUGR.

$\square \square$ Absent end diastolic flow and Reverse diastdic flow in umbilical artery indicatessevere fetal distress and is associated with $100 \%$ perintal mortality.

$\square \square$ Abnormal PI of MCA/ umbilical artery ratio is also associated with IUGR.

CPR is more sensitive than MCA and umbilical artery.

$\square \square$ Because the chages in the uterine and umbilical circulation strongly correlatewith the perinatal outcome, Doppler velocimetry is a primary tool for fetomaternalsurveillance in hypertensive pregnancy.

$\square \square$ It is safe, noninvasive technique, easy to perform, easy to interpret, and hencemost valuable tool in the management of high risk pregnancy.

$\square \square$ There was high incidence of LSCS due to fetal distress, low birth weight,increased incidence of NICU admission and low Apgar score at 1 and 5 minuteswith abnormal Doppler indices in the study group.

$\square$ Thus triple vessel Doppler study is very useful in predicting high riskpregnancies with adverse perinatal outcome when the Doppler velocimetry isabnormal

\section{References}

[1]. Aris T. Papageorghious, Christian K H. Yu, II se E. Erasmur, Howard S.Cuckle.,Kypros H. Nicolaides, Br. J. ObstetGynaecol June 2005, vol.112 pp-707-709

[2]. ChappelI.Bewley S: Pre-eclampticToxemia. The Role of uterine artery DopplerBr.J .Obstetgynaecol 105, 379-382; 1998.

[3]. ACOG committee on obstetrics practice ACOG practice bulletin diagnosis andmanagement of pre-eclampsia and eclampsia,. Number 33, January 2002,American college of obstetrician and gynecologist, Int. J. Gynaecol 2002; 77; 65-75.

[4]. Schulman H, FleiscerA Steen W, FarmakidesG.Jagani N. Blattner P Umbilicalvelocity wave rations in human pregnancy Am J Obstetgynaecol 1984, 148:985-90.

[5]. Deane C, Harrington K. A practical approach to obtaining optimum Dopplersignals. In: Harrington K, Campbell S, editors. A colour atlas of Dopplerultrasonography in obstetrics. London: Arnold, 1995: 35-46.6. Fitzgerald DE, Drumm JE. Non-invasive measurement of human fetal circulationusing ultrasound: a new method. BMJ 1977; 2:1450-1451.

[6]. Kok JH, den Ouden AL, Verloove-Vanhorick SP, Brand R. Outcome of verypreterm small for gestational age infants: the first nine years of life. Br J ObstetGynaecol 1998; 105:162-168.

[7]. Cohn HE, Sacks EI, Heyman MA, Rudolph AM. Cardiovasculas responses tohypoxemia and academia in fetal lambs. Am J ObstetGynaecol 1974;120:817-21.

[8]. Peeters LH, Sheldon RE, Jones MD, et al. Blood flow to fetal organs as afunction of arterial oxygen content. Am J ObstetGynecol 1979; 135:637-646.

[9]. Campbell S. Fetal growth. In: Nathanielz P, Beard R, eds. Fetal physiology andmedicine. Bournemouth, United Kingdom: Saunders, 1974:271-300.

[10]. Arbeille PH, Roncin A, Berson M, Pourcelot L. Exploration of the fetal cerebralblood flow by duplex Doppler-Linear array system in normal and pathologicapregnancies. Ultrasound Med Biol 1987; 13: 329-32.

[11]. Waldimiroff JW, Wijingaard JAGW, Degani S, Noordam MJ, Eyck J, TongeHM.Cerebral and umbilical arterial blood flow velocity waveforms in normal andgrowth retarded pregnancies. ObstetGynaecol 1987; 69:705-9.

[12]. Gramellini D, Folli MC, Raboni S, Vadora E, Merialdi A. Cerebral-umbilicalDoppler ratio as a predictor of adverse perinatal outcome. ObstetGyneacol 1992;74:416-420.

[13]. Arias F. Accuracy of the middle cerebral to umbilical artery resistance indexratios in the prediction of perinatal outcome in patients at high risk for fetal andneonatal complications. Am J ObstetGynaecol 1994; 171:1541-1545.

[14]. Bahado-singh RO, Kovanci E, Jeffres A, Utku OZ, Deren O, copel J et al. TheDoppler cerebroplacental ratio and perinatal outcome in intrauterine growthrestriction. Am J ObstetGynaecol 1999; 180:750-756.

[15]. Vyas S, Nicolaides KH, Bower S, Campbell S. Middle cerebral artery flow velocity waveforms in fetal hypoxaemia. Br J ObstetGynaecol 1990 Sep; 97(9):797-803.

[16]. Harrington K, Carpenter RG, Nguyen M, Campbell S: Changes observed in Doppler studies of the fetal circulation in pregnancies complicated by preeclampsia or the delivery of a small-for-gestational age baby. I. Cross-sectional analysis.UltrasoundObstetGynecol 1995; 6(1):19-28.

[17]. Chan FY, Pun TC, Lam P, Lam C, Lee CP, Lam YH. Fetal cerebral Doppler as a predictor of perinatal outcome and subsequent neurological handicap. ObstetGynecol 1996; 87:981-988.

[18]. Mohd.Khalid, ShaguftaWahab, Vijay Kumar, Saifullah Khalid, Soafia Haroon, Noor A. Sabzposh. Doppler indices in prediction of fetal outcome in hypertensive pregnant women. Nepal J Obstet\&Gynaecol. 2011 May-June; 6(1): 28-34.

[19]. Bhatt CJ, Arora J, Shah MS . Role of color Doppler in pregnancy induced hypertension (A study of 100 cases) Indian J. Radiol Imaging 2003: 13: 417-420.

[20]. Gupta U, Qureshi A and Samal S. Doppler velocimetry in normal and hypertensive pregnancy. The Internet Journal of Gynecology and Obstetrics. 2009; 11:2. 
[21]. Saxena K, Khan T, Tandon R. Umbilical artery flow and its correlation with fetal outcome in normal and hypertensive pregnancy. Ind Med Gazette. 1996; 236-239.

[22]. Battaglia C, Artini PA, Galti G et al. Absent or reverse end diastolic flow in umbilical artery and severe intrauterine growth retardation.ActaObstetGynecol Scand. 1992; 72: 167-171.

X. Tables

Table-1: Age Distribution of Cases

\begin{tabular}{|c|c|c|}
\hline Age (Years) & Study Group & Control Group \\
\hline$<\mathbf{2 0}$ & $\mathbf{3}$ & $\mathbf{6}$ \\
\hline $\mathbf{2 0 - 2 4}$ & 34 & 36 \\
\hline $\mathbf{2 5 - 2 9}$ & 11 & 5 \\
\hline$>\mathbf{3 0}$ & 2 & 3 \\
\hline
\end{tabular}

Table -2: Gestational Age Distribution in study group and control group

\begin{tabular}{|c|c|c|}
\hline Gestational age (Wk) & Study Group & Control Group \\
\hline $31-32$ & 9 & 0 \\
\hline $33-34$ & 5 & 1 \\
\hline $35-36$ & 10 & 3 \\
\hline $37-38$ & 19 & 37 \\
\hline $39-40$ & 7 & 9 \\
\hline
\end{tabular}

Table -3: Distribution Characteristics of Placental Maturity

\begin{tabular}{|c|c|c|}
\hline Placental Grading & Study Group & Control Group \\
\hline $\mathbf{2}$ & $\mathbf{3 4}$ & $\mathbf{4 3}$ \\
\hline $\mathbf{3}$ & $\mathbf{1 6}$ & $\mathbf{7}$ \\
\hline Total & $\mathbf{5 0}$ & $\mathbf{5 0}$ \\
\hline
\end{tabular}

Table -4: Amniotic Fluid distribution in the study group

\begin{tabular}{|c|c|c|c|}
\hline Amniotic Fluid & Doppler Normal & Doppler Abnormal & Total \\
\hline Oligo & 2 & 13 & 15 \\
\hline Normal & 17 & 18 & 35 \\
\hline Total & 19 & 31 & 50 \\
\hline
\end{tabular}

Table -5: Maternal complications of study group

\begin{tabular}{|c|c|c|}
\hline Maternal Complications & Number Of Cases & Percentage \\
\hline Iugr & 22 & 44 \\
\hline Anaemia & 8 & 16 \\
\hline Previous Lscs & 2 & 4 \\
\hline Help Syndrome & 3 & 6 \\
\hline
\end{tabular}

Table -6: Pregnancy Outcome in the study group

\begin{tabular}{|c|c|c|c|c|}
\hline $\begin{array}{c}\text { Pregnancy } \\
\text { outcome }\end{array}$ & \multicolumn{2}{|c|}{ No. of cases } & \multicolumn{2}{c|}{ Percentage } \\
\hline & $\begin{array}{c}\text { Study } \\
\text { group }\end{array}$ & Control group & Study group & Controlgroup \\
\hline Adverse & 42 & 10 & 84 & 20 \\
\hline Uneventful & 8 & 40 & 16 & $\mathbf{8 0}$ \\
\hline Total & 50 & 50 & 100 & 100 \\
\hline
\end{tabular}

Table -7: Adverse outcome Parameters in Study and Control Groups

\begin{tabular}{|c|c|c|c|c|}
\hline $\begin{array}{c}\text { Pregnancy } \\
\text { outcome }\end{array}$ & \multicolumn{2}{|c|}{ No. of cases } & \multicolumn{2}{c|}{ Percentage } \\
\hline & $\begin{array}{c}\text { Study } \\
\text { group }\end{array}$ & $\begin{array}{c}\text { Control } \\
\text { group }\end{array}$ & Study group & $\begin{array}{c}\text { Control } \\
\text { group }\end{array}$ \\
\hline EmLSCS & $\mathbf{1 5}$ & 9 & 30 & 18 \\
\hline Low Apgar Score & $\mathbf{8}$ & 0 & 16 & 0 \\
\hline NICU Admission & $\mathbf{1 9}$ & 0 & 38 & 0 \\
\hline Neonatal Death & $\mathbf{8}$ & 0 & 16 & 0 \\
\hline Low Birth Weight & $\mathbf{3 5}$ & 7 & 70 & 14 \\
\hline Preterm Delivery & $\mathbf{2 4}$ & 3 & 48 & 6 \\
\hline
\end{tabular}

$70 \%$ of neonates $(n=35)$ had birth weight of less than $2.5 \mathrm{~kg}$. Of the 50 neonates, 19 neonates were admitted to NICU, 8 neonates had 5 min Apgar score of less than 7 and 15babies were born by emergency caesarian section for fetal distress. 
Study Of Triple Vessel Wave Pattern Bydoppler Studies In Low Risk And High.....

Table-8: Normal and Abnormal Doppler Wise Distribution of Cases

\begin{tabular}{|c|c|c|}
\hline Doppler & Number & Percentage \\
\hline Normal & $\mathbf{1 6}$ & $\mathbf{3 2}$ \\
\hline Abnormal & $\mathbf{3 4}$ & $\mathbf{6 8}$ \\
\hline Total & $\mathbf{5 0}$ & $\mathbf{1 0 0}$ \\
\hline
\end{tabular}

Table -9: Doppler velocimetry of umbilical artery and perinatal outcome

$\square 2=31.04$

\begin{tabular}{|c|c|c|c|c|c|c|}
\hline & \multicolumn{2}{c|}{$\begin{array}{c}\text { Complications or } \\
\text { death }\end{array}$} & \multicolumn{2}{c|}{ Live or healthy } & \multicolumn{2}{c|}{ Total } \\
\hline Abnormal & 14 & $93.3 \%$ & 1 & $6.7 \%$ & 15 & 100 \\
\hline Normal & 8 & $22.85 \%$ & 27 & $77.14 \%$ & 35 & 100 \\
\hline Total & 22 & $44 \%$ & 28 & $56 \%$ & 50 & 100 \\
\hline
\end{tabular}

$\mathrm{DF}=1$

$\mathbf{P}<0.001$

There is significant association between Doppler study result of umbilical artery andperinatal outcome

Table -10: Doppler velocimetry of middle cerebral artery and perinatal outcome

$\square=17.39$

\begin{tabular}{|c|c|c|c|c|c|c|}
\hline & \multicolumn{2}{|c|}{$\begin{array}{c}\text { Complications } \\
\text { or } \\
\text { death }\end{array}$} & \multicolumn{2}{|c|}{ Live or healthy } & \multicolumn{2}{|c|}{ Total } \\
\hline Abnormal & $\mathbf{2 1}$ & $\mathbf{7 2 . 4 1 \%}$ & $\mathbf{8}$ & $\mathbf{2 7 . 5 \%}$ & $\mathbf{2 9}$ & $\mathbf{1 0 0}$ \\
\hline Normal & 7 & $\mathbf{3 3 . 3 \%}$ & $\mathbf{1 4}$ & $\mathbf{6 6 . 7 \%}$ & $\mathbf{2 1}$ & $\mathbf{1 0 0}$ \\
\hline Total & $\mathbf{2 8}$ & $\mathbf{5 6 \%}$ & $\mathbf{2 2}$ & $\mathbf{4 4 \%}$ & $\mathbf{5 0}$ & $\mathbf{1 0 0}$ \\
\hline
\end{tabular}

$\mathrm{DF}=1$

$\mathbf{P}<\mathbf{0 . 0 0 1}$

There is significant association between Doppler study result of middle cerebral artery and perinatal outcome

Table -11: Diastolic notch of uterine artery and perinatal outcome.

\begin{tabular}{|c|c|c|c|c|}
\hline No. of cases & \multicolumn{2}{|c|}{ Adverse outcome } & \multicolumn{2}{c|}{ Live \& Healthy } \\
\hline 20 & 11 & $55 \%$ & 9 & $45 \%$ \\
\hline
\end{tabular}

Table-12: Cerebro-placental ratio (MCA PI/UA PI) in prediction of IUGR

\begin{tabular}{|c|c|c|}
\hline Parameters & No. of IUGR Cases & Percentage \\
\hline CPR $<1$ & 16 & 72.73 \\
\hline CPR $>1$ & 6 & 27.27 \\
\hline Total & 22 & 100 \\
\hline
\end{tabular}

Table -13: Spectral characteristics of umbilical artery and perinatal outcome.

\begin{tabular}{|c|c|c|c|}
\hline & No. of cases & Mortality & Percentage \\
\hline AEDF & $\mathbf{0 5}$ & $\mathbf{0 5}$ & $\mathbf{1 0 0}$ \\
\hline REDF & $\mathbf{0 1}$ & $\mathbf{0 1}$ & $\mathbf{1 0 0}$ \\
\hline
\end{tabular}

Table-14: Performance Characteristics of Doppler Indices

\begin{tabular}{|c|c|c|c|c|c|}
\hline Parameters & Sensitivity & Specificity & PPV & NPV & $\begin{array}{c}\text { Diagnostic } \\
\text { Accuracy }\end{array}$ \\
\hline UA PI & $\mathbf{6 6 . 6 6}$ & $\mathbf{9 3 . 1 0}$ & $\mathbf{8 7 . 5 0}$ & $\mathbf{7 9 . 4 0}$ & $\mathbf{8 2}$ \\
\hline MCA PI & $\mathbf{8 3 . 3 3}$ & $\mathbf{8 5}$ & $\mathbf{8 9 . 2 8}$ & $\mathbf{7 7 . 2 7}$ & $\mathbf{8 4}$ \\
\hline CPR & $\mathbf{9 5}$ & $\mathbf{8 7}$ & $\mathbf{8 8}$ & $\mathbf{8 5}$ & 90 \\
\hline
\end{tabular}

\section{Legends}

Figure-1: Normal uterine artery wave form Figure-2: Normal Umbilical Artery wave Figure-3: Normal MCA wave formFigure-4: Umbilical artery with decreased diastolic flow Figure-5 :Umbilical artery with AEDF Figure-6 :Umbilical artery with REDF Figure-7: Uterine Artery with NotchFigure 8: MCA with Decreased PI 


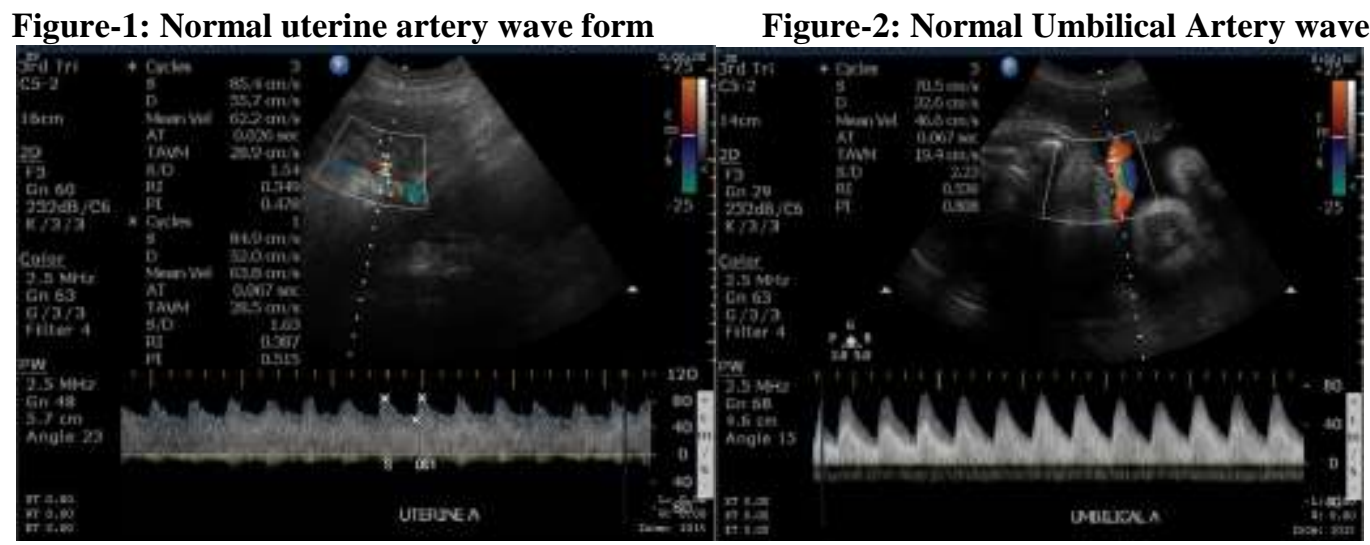

Figure-3: Normal MCA wave formFigure-4: Umbilical artery with decreased diastolic flow

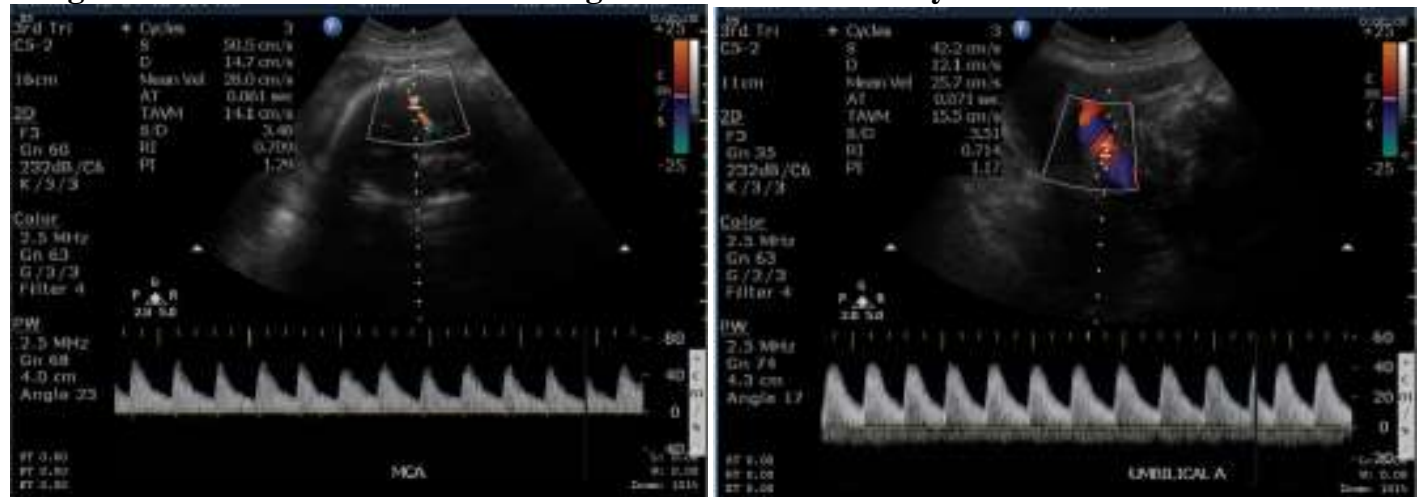

Figure-5: Umbilical artery with AEDF Figure-6 :Umbilical artery with REDF

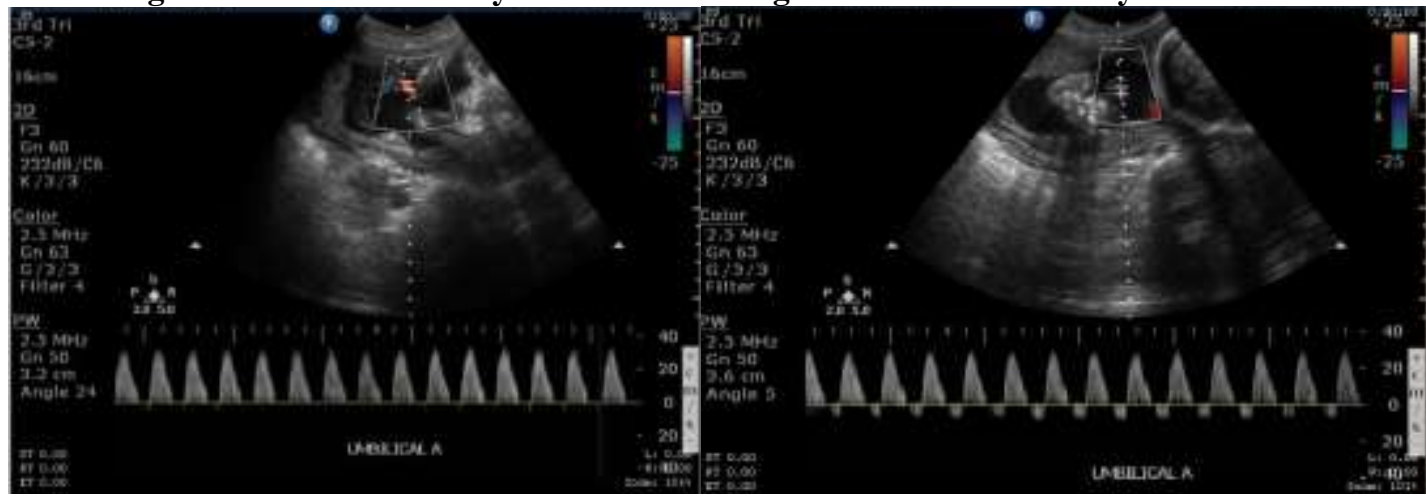

Figure-7: Uterine Artery with Notch Figure 8: MCA with Decreased PI

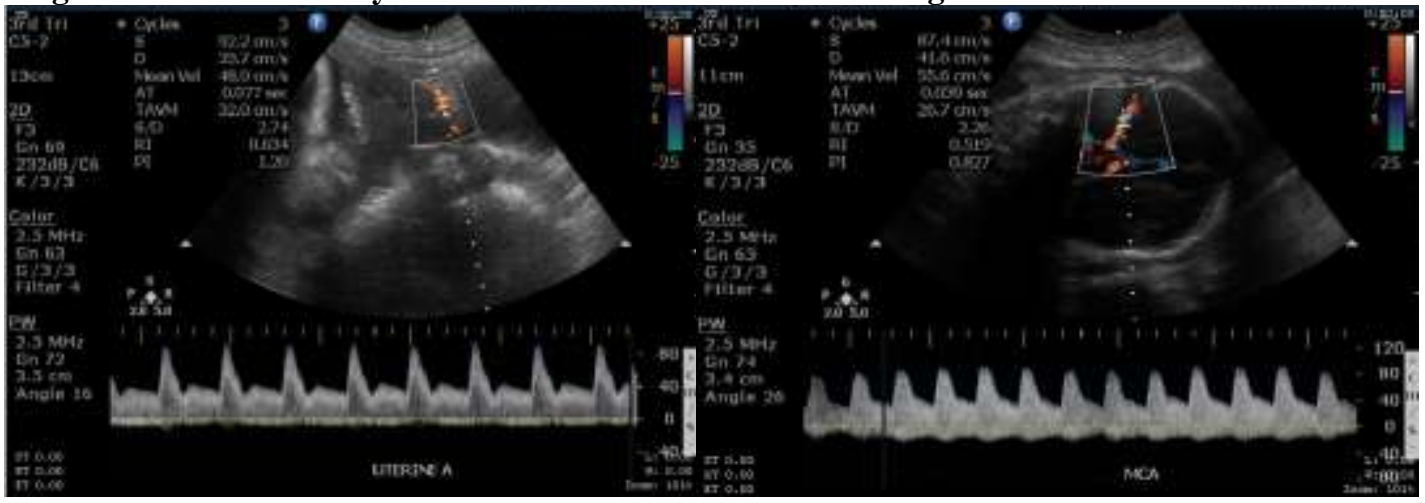

